\section{$\underset{\substack{\text { hommes } \\ \text { \& migrations }}}{ }$}

\section{Hommes \& migrations}

Revue française de référence sur les dynamiques

migratoires

1317-1318 | 2017

L'Europe en mouvement

\title{
Négar Djavadi, Désorientale
}

Paris, Liana Levi, 2016, 350 p., $22 €$.

\section{Mustapha Harzoune}

\section{OpenEdition}

1 Journals

\section{Édition électronique}

URL : http://journals.openedition.org/hommesmigrations/3943

DOI : 10.4000/hommesmigrations.3943

ISSN : 2262-3353

\section{Éditeur}

Musée national de l'histoire de l'immigration

\section{Édition imprimée}

Date de publication : 1 avril 2017

Pagination : 198-199

ISBN : 978-2-919040-38-4

ISSN : $1142-852 X$

Référence électronique

Mustapha Harzoune, « Négar Djavadi, Désorientale », Hommes \& migrations [En ligne], 1317-1318|

2017, mis en ligne le 01 avril 2017, consulté le 23 septembre 2020. URL : http://

journals.openedition.org/hommesmigrations/3943; DOI : https://doi.org/10.4000/

hommesmigrations.3943 


\section{LIVRES}

moi, avec l'envie de taper, de mordre, de rentrer dedans $"$ ? dit Ismaël saïd, atias Bruce devenu le chef de Gaza, un ghetto à la lisière de Mamoudzou, "un immense camp de clandestins ì ciel ouvert, c'est une énorme poubelle fumante que l'on voit de loin. Gaza c'est un no man's land violent où les bandes de gamins shootés au ehimique font la loi. Gaza c'est cape Iown, c'est Calcutta, c'est Rio. Gazz c'est Mayotte, Gaza c'est la France. " Bruce déteste Mö̈se et ses " mots bien propres, bien ordonnés, des mots bien français, bien blancs $"$. Hexècre tes journalistes et autres "Blanes " qui viennent à Gaza comme ils vont au cinéma, avec de grands mots et de belles théories... D'ailleurs, matgré les enquêtes et tes rapports, tes promesses des politiciens véreux qui arrosent te bidonville le temps d'une élection, Mayotte est au bord de l'explosion. "Nous sommes seu/s. " Seuls surcette partie intégrante du territoire nationat où la viotence est omniprésente: viol, exploitation sexuelle, rapports de domination, misère et avilissement des relégués, jusqu'àl'odeur du ghetto,

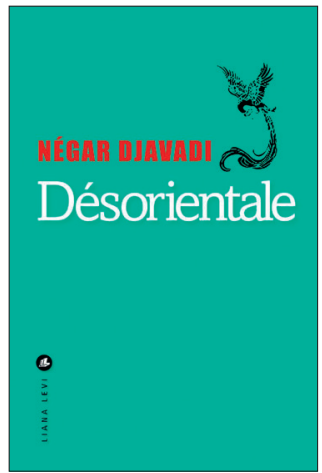
C'est bien du côté des littératures dites de l'exil que s'écrit - et se joue - le devenir national et, au-delà, une partie du destin du monde. Sans boursoufflure, il faut jusqu'aux corps défigurés par la haine et les souffrances. Et, bien sûr, il y a tes etandestins. En surnombre. Ceux qui ont échappé à la mort, entre Anjouan et Mayotte trainent " avec des cancers teltement avancés qu'its niexistent plus, en métropote, que dans tes livres de médecine. J'aivu de grands brûtés à la peau toute pourrie, des bébés morts depuis plusieurs jours mais toujours dans les bras de leurs meres, des hommes aux jambes sectionnées par des requins". Nathacha Appanah décrit l'insupportable sans porter de jugement. Cela tient au ton, mais aussi à l'exposition, de chapitre en chapitre, des angtes (et non des points) de vue des trois protagonistes auxquets s'ajoutent les voix d'un policier et d'un éducateur. Elle réussit à provoquer cette disponibilité, non pas empathique, mais écoute, une sorte de tuishou lla poussée des mains au taî-chi) tittéraire. Écouter, pour mieux sentir les logiques collectives à foeuvre et comment chacun s'efforce de sortir la tête de l'eau, fusse pour une seute bouffée d'oxygène. Avant de transformer l'innocenten assassin. M. H.

reconnaître, dire et redire que ces auteurs sont les sismographes des temps modernes, les géologues attentifs de la tectonique des peuples, les cartographes des nouvelles appartenances et des nouveaux imaginaires. Ils rincent le cœur et l'âme des biles de « l'autofiction névrotique parisienne " (dixit Andreï Makine, discours de réception à l'Académie française). Les uns ouvrent, les autres (en)ferment. 
Négar Djavadi est de ces romanciers français à la plume de métèque. Rappel, aux atrabilaires de l'identité, aux hypocondriaques de la langue française : les ambassadeurs de cette "ressource " culturelle (François Jullien), celles et ceux qui la défendent en la faisant vivre, ce sont ces rastaquouères débarqués dans le pré carré national. Certainement pas ces politiques au vocabulaire anorexique incapables d'aligner deux tristes phrases sans débiter une joyeuse bourde.

Et, côté langue, Négar Djavadi ne manque pas de billes! Elle écrit un français d'inspiration classique, tout en reliefs. Physique, sensible, visuel. Elle peut se détourner des effets de manche - être directe, percutante, drôle-comme progresser en circonvolutions et métaphores pour transfuser tensions, colères, tendresses, frustrations, attentes, désillusions... Tout devient pudique, élégant, les mots traduisant le raffinement des comportements et de la pensée.

Négar Djavadi a quitté l'Iran à 11 ans, sans doute dans les bagages de ses réfugiés (!) de parents. Comme Kimiâ, l'héroïne et narratrice. Désorientale, c'est l'exil à l'iranienne. Le titre traduit le processus de désintégration que cache l'exigence - et les réussites - d'intégration, rejoignant en cela Doan Bui. Négar Djavadi a choisi de raconter en plusieurs tableaux un dédale d'aller-retour, passant de lointaines origines familiales, dans un harem du côté de Mazandaran, à la branche arménienne et maternelle. Navigant entre les souvenirs d'une enfance heureuse et les cruautés et les injustices d'un exil bricolé en recompositions et reconstructions, hanté par les djinns du passé et de la dépression. Fuyant l'Iran de la Savak, puis des mollahs pour une France qui marchande son hospitalité. Quittant la « grande schizophrénie muette " d'une petite fille pour un service de PMA de l'hôpital Cochin à Paris. Dans la salle d'attente, Kimiâ, un tube de sperme congelé et lavé entre les mains, raconte la saga des Sadr. L'histoire de ses parents, Sara et Darius, son communiste de mari, opposants au régime du Shah, puis à celui des mollahs. Couple lumineux et tendrement complice. Vertical. Fragile. C'est fort. Efficace. Bouleversant. Négar Djavadi distille de savoureuses saillies. Sur la mémoire. Les différences culturelles. Sur les vertus de la démocratie ("Qui irait prier à la mosquée quand son enfant tombe malade s'il a la sécurité sociale et un hôpital à proximité ? Qui s'accrocherait à la robe des mollahs s'il a une administration pour l'écouter? ")... Le lecteur, plusieurs fois interpellé, a même droit à une philosophie de l'Histoire et une éthique du comportement à la sauce... punk !

Et il y a le poil à gratter : l'idéalisation de la France qui s'écrase sur un mur d'indifférence ou d'ignorance. Comme les responsabilités américaines dans la chute de Mossadegh en 1953 ou françaises dans l'arrivée du « vieillard enturbanné » et "dans les événements qui suivirent».

Désorientale, c'est la PMA appliquée aux mots et aux imaginaires. Une maïeutique qui révèle l'interdépendance des peuples comme les multiples et nouvelles façons d'être au monde et aux autres. C'est vrai pour les exilés. Mais pas uniquement.

M. H. 